\title{
Real-Time Monitoring of Active Landslides
}

andslides threaten lives and
property in every State in the
Nation. To reduce the risk from
active landslides, the U.S.
Geological Survey (USGS) develops
and uses real-time landslide moni-
toring systems. M onitoring can
detect early indications of rapid,
catastrophic movement.
Up-to-the-minute or real-time
monitoring provides immediate
notification of landslide activity,
potentially saving lives and property.
Continuous information from
real-time monitoring also provides
a better understanding of landslide
behavior, enabling engineers to
create more effective designs for
halting landslide movement.

D uring heavy rains in January 1997, thousands of tons of earth gave way in the Sierra Nevada, destroying three homes, blocking a major northern California highway (U.S. 50), and briefly damming the adjacent American River. Waters dammed by the landslide quickly flooded two vehi-

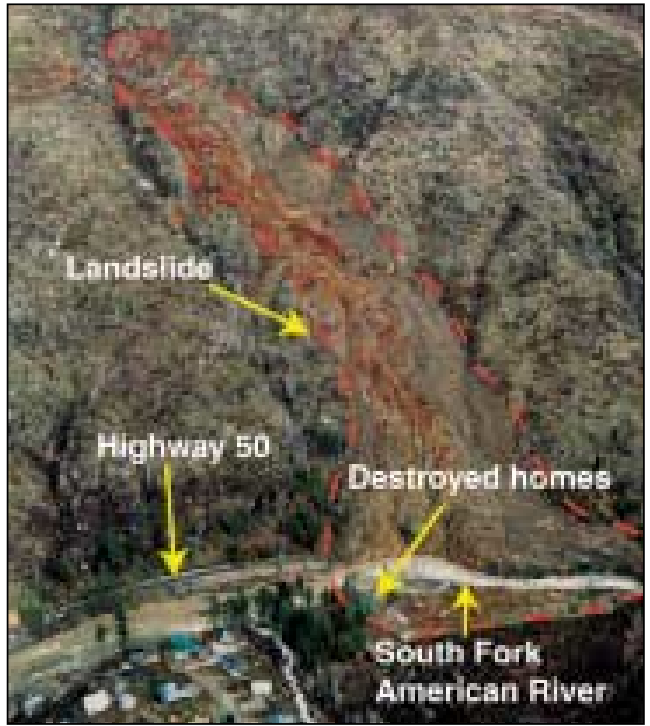

Massive landslide that blocked Highway 50 and temporarily dammed the South Fork of the American River (Photo: Lynn Harrison, Caltrans)

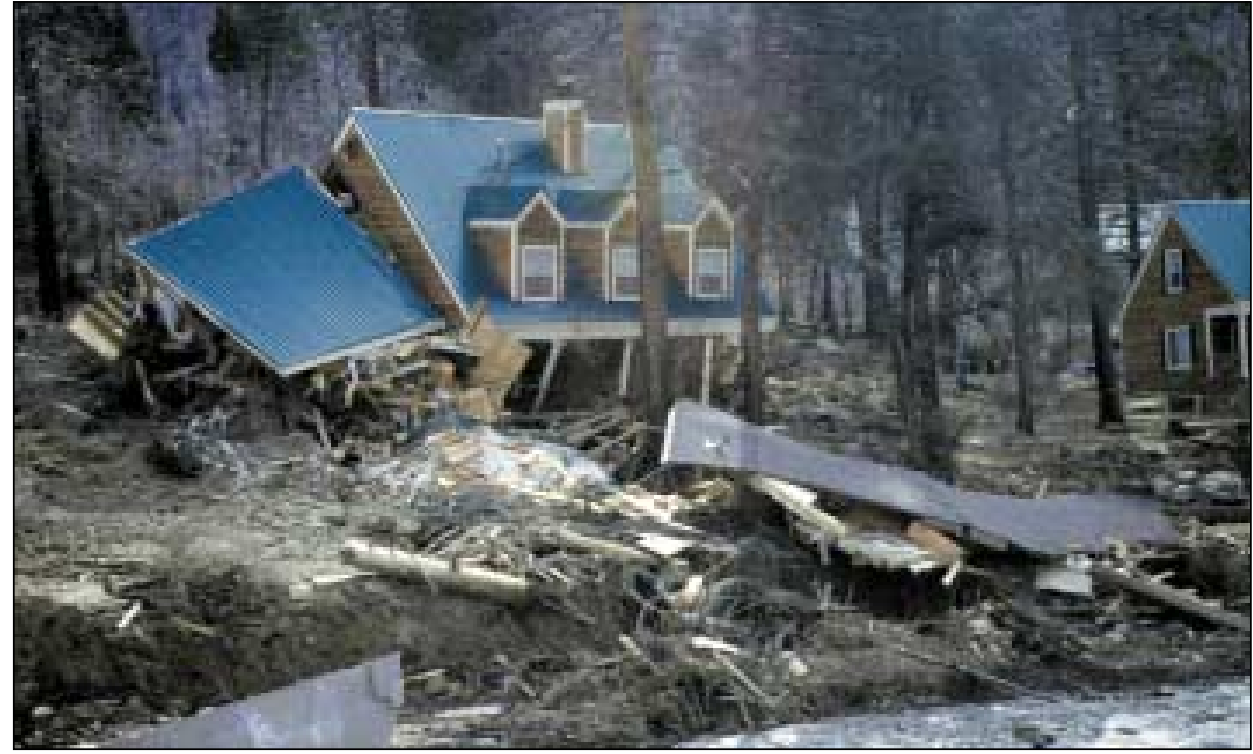

Homes destroyed by a sudden catastrophic landslide in 1997 along U.S. Highway 50, about 25 miles east of Placerville, California (Photo: M ark Reid, USGS)

cles traveling on the highway, leading to dramatic rescues. Reopening the highway cost \$4.5 million, and indirect economic losses from the highway closure exceeded $\$ 50$ million.

Several large, active landslides in the same area continue to threaten U.S. Highway 50 . Although these slides often move slowly, some have the potential to collapse catastrophically. To help reduce the risk posed by these landslides, the USGS, in cooperation with other agencies, acted quickly to provide continuous real-time monitoring of landslide activity using systems developed by the USGS for monitoring active volcanoes in remote areas. Data from a variety of sensors installed at the landslides are transmitted by radio to USGS computers. Graphs of sensor response are available over the Internet to local officials, geotechnical engineers, and emergency managers.

Why is it necessary to collect real-time landslide data remotely? The immediate detection of landslide activity provided by

\section{When do landslides turn catastrophic?}

$M$ any landslides are inactive during dry times and move only during or following extended periods of infiltration from rain or melting snow. Increased water pressure in the ground reduces the overall strength of hillsides and starts downslope movement, but landslide speed and potential destructiveness can vary widely. Some landslides move slowly, traveling only a few inches in many days. Other landslides can transform suddenly into mud or debris flows that travel thousands of feet in a matter of minutes, cause massive destruction, and kill people.
M onitoring can determine the speed of landslide movement and can also detect early indications of catastrophic movement. Rapid movement at some landslides, for example, is preceded by gradual acceleration. Using real-time data from such slides, geologists can anticipate possible catastrophic movement. USGS landslide monitoring focuses on detecting (1) precipitation and ground-water conditions that could destabilize a hillslope, (2) acceleration of slide movement, and (3) ground vibrations associated with movement. 


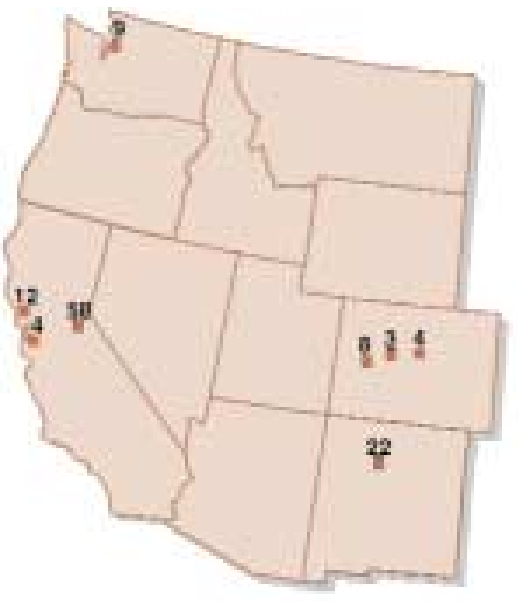

a Landslide manitoring sites

Current USGS remote landslide monitoring sites in the western United States (number indicates number of sensors in each area)

real-time systems can be crucial in saving human lives and protecting property.

Traditional field observations, even if taken regularly, cannot detect changes at the moment they occur. Moreover, active landslides can be hazardous to work on, and large movements often occur during storms when visibility is poor. The continuous data provided by remote real-time monitoring permits a better understanding of dynamic landslide behavior that, in turn, enables engineers to create more effective designs to prevent or halt landslides.

At landslide areas remotely monitored by the USGS, ground movement and groundwater pressures are measured every second. The amount of downslope movement is recorded by extensometers that can detect stretching or shortening of the ground. Ground vibrations caused by slide movement are monitored by geophones buried within the slides. Ground-water conditions within the slides are monitored by porewater-pressure sensors, and on-site rain gauges record precipitation. Under normal

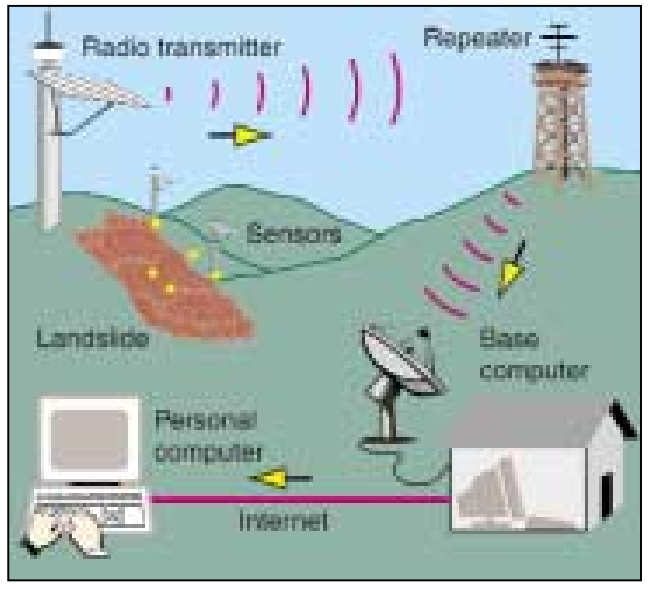

Netw ork for transmission of real-time landslide data conditions, data are transmitted to USGS computers every 10 minutes, but data are transmitted immediately if strong ground vibrations caused by massive landslide movement are detected.

Currently, five landslides along U.S.

Highway 50 are monitored in real-time using 58 instruments. This network, operated in cooperation with the California Department of Transportation, provides engineers and geologists with early notification of landslide activity and with information useful in the design of remedial measures to halt these slides. Real-time data from one of these landslides is available to the public over the Internet at http://landslides.usgs.gov/hwy50.

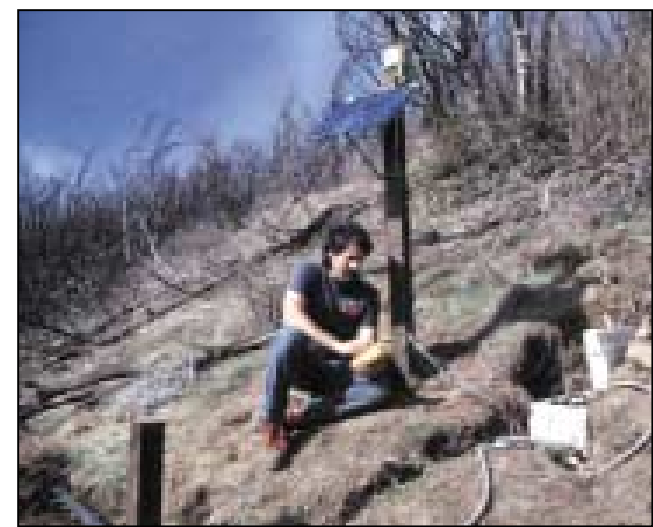

Above: Testing a solar-powered radio telemetry system for remote transmission of real-time landslide data (Photo: M ark Reid, USGS)

Right: M easuring landslide movement using an extensometer (an instrument that can detect stretching of the ground surface between stable ground and sliding ground) (Photo: Richard LaHusen, USGS)

The USGS operates other remote real-time landslide monitoring sites. Near Seattle, Washington, a real-time system monitors a slide threatening a major railway

(http://landslides.usgs.gov/woodway), and in Rio Nido, California, another system monitors a large landslide threatening more than 140 homes. Remote monitoring by the USGS in Fremont, California, detects landslide movement threatening downslope homes, and in New Mexico, remote monitoring records the effects of wildfire in destabilizing hillslopes. In Colorado, remote monitoring at several landslide sites provides notification of ground movement caused by large slow landslides or by rapid debris flows.

Active ground movement, including landsliding, occurs in every state in the Nation. To help reduce the risk from landslide hazards, scientists at the USGS have developed real-time monitoring and other tools that help in understanding and predicting where, when, and how landslides occur. USGS scientists also provide technical assistance to local authorities during landslide disasters. The work of the USGS Landslide Hazards Program is helping to protect people's lives and property from landslide hazards throughout the United States.

Mark E. Reid

Richard G. LaHusen W illiam L. Ellis

\section{Cooperating Organizations}

California Department of Transportation

California Division of M ines and Geology

California Office of Emergency Services

City of Fremont, California

Colorado Department of Transportation

Colorado Geological Survey

Federal Emergency M anagement Agency

Garfield County, Colorado

National Park Service

Pitkin County, Colorado

Sonoma County, California

U. S. Bureau of Land M anagement

U. S. Department of Agriculture, Forest Service

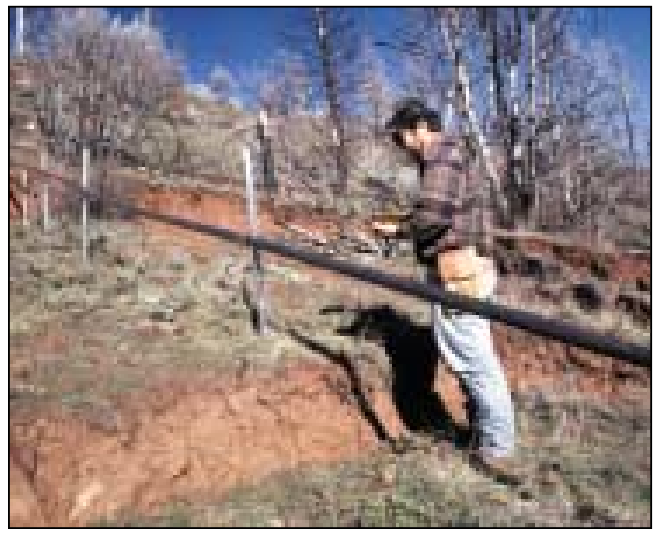

\section{For more information:}

National Landslide Information Center

U.S. Geological Survey, Federal Center

Box 25046, M S 966, Denver, CO 80225 1-800-654-4966

http://landslides.usgs.gov

N LIC@usgs.gov

Real-time monitoring:

http://landslides.usgs.gov/monitoring/hwy50/ http://landslides.usgs.gov/regional/seattle/ 